\title{
The unexpected formation of a dihydroisobenzofuran derivative from the addition of a Grignard reagent to a 1,3-indanedione
}

\author{
James Vile, Mariolino Carta, C. Grazia Bezzu, James Dee, and Neil B. McKeown* \\ School of Chemistry, Cardiff University, Cardiff, CF10 3AT \\ E-mail: McKeownnb@cardiff.ac.uk
}

Dedicate to Professor Keith Smith on the occasion of his $65^{\text {th }}$ anniversary

\begin{abstract}
Despite good literature precedents, the addition of excess 2-biphenylmagnesium bromide to 4,5dimethoxy-1,3-indanedione, followed by acid work-up, did not give the desired diol precursor to an Organic Molecule of Intrinsic Microporosity. Instead a dihydroisobenzofuran derivative was isolated in moderate yield and its structure characterised fully by single crystal X-ray crystallography. It is suggested that this product is formed by sequential Grignard addition, retroaldol reaction, a second Grignard addition and acid-mediated formation of the dihydroisobenzofuran ring.
\end{abstract}

Keywords: Grignard reagent, retro aldol, 1,3-indanedione, intrinsic microporosity, X-ray crystallography

\section{Introduction}

Generally, organic molecules form crystalline solids as the constituent molecules pack such that the intermolecular attractions are maximised and the amount of free space is minimised, thus efficient packing occurs. However, molecules with 'awkward' structures do not pack space efficiently and form clathrate crystals containing solvent. In theory, removal of the included solvent can result in a crystalline nanoporous crystal $^{1}$ or an amorphous material that could possess microporosity, like that found in macromolecular systems such as the Polymers of Intrinsic Microporosity (PIMs). ${ }^{2}$ In PIMs, the microporosity arises from the rigid and contorted nature of the polymer chains. However intrinsic microporosity is not solely a property of macromolecular systems and we have found that discrete, structurally well-defined molecules of modest molecular mass can also generate intrinsic microporosity. In a recent paper $^{3}$ we anticipated the possibility to synthesise Organic Molecules of Intrinsic Microporosity (OMIM) by fusing rigid structural units to a rigid biphenyl core. For example OMIM-1 was prepared by 
the reaction between 2,3-dihydroxytriptycene and 4,4'-dicyano-2,2',3,3',5,5',6,6'octafluorobiphenyl via the aromatic nucleophilic substitution which gives fused dibenzodioxan linkages. Nitrogen adsorption demonstrated that OMIM-1 is microporous with an apparent BET surface area of $600 \mathrm{~m}^{2} \mathrm{~g}^{-1}$. Based on the interesting properties of OMIM-1, it was desirable to synthesise further examples so that the properties of these molecular materials can be better understood. Hence, we are interested in designing bulky, rigid structural units with single catechol units that could also react smoothly with 4,4'-dicyano-2,2',3,3',5,5',6,6'octafluorobiphenyl. In particular, previous work on PIMs has shown that microporosity can be enhanced by the addition of fluorene substituents fused via a spiro-centre. ${ }^{4}$ Hence, we attempted the formation of the bulky catechol derivative $\mathbf{1}$ (Scheme 2) as a precursor to an OMIM.
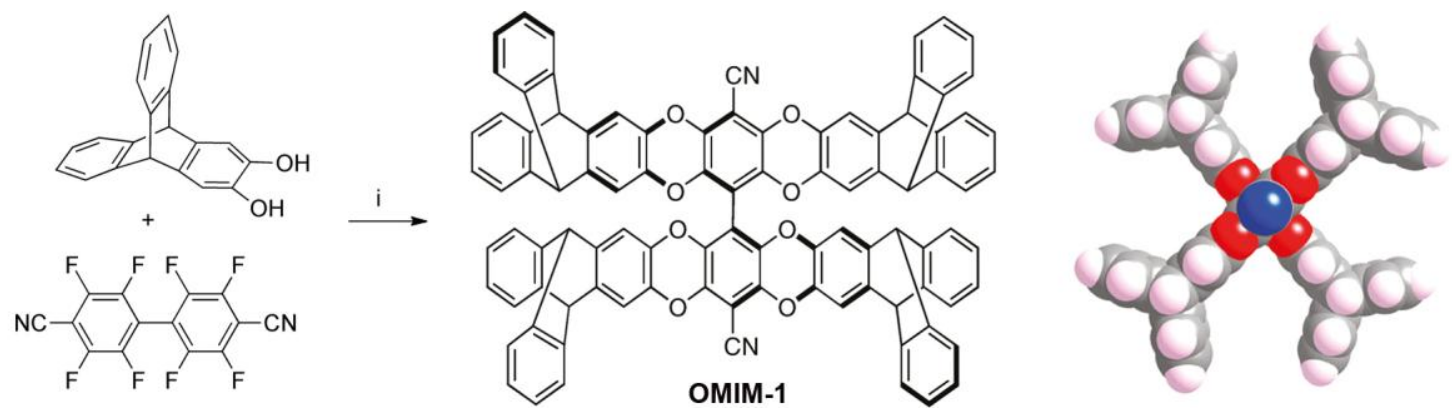

Scheme 1. The synthesis and space-filling molecular model of OMIM-1 looking down the axis of the biphenyl core.

The proposed route to $\mathbf{1}$ involves the addition of an excess of the Grignard reagent from 2bromobiphenyl to 5,6-dimethoxy-1,3-indandione 2. Acid-mediated electrophilic cyclisation of the resulting adduct $\mathbf{3}$ followed by cleavage of the methoxy groups was anticipated to yield catechol 1.

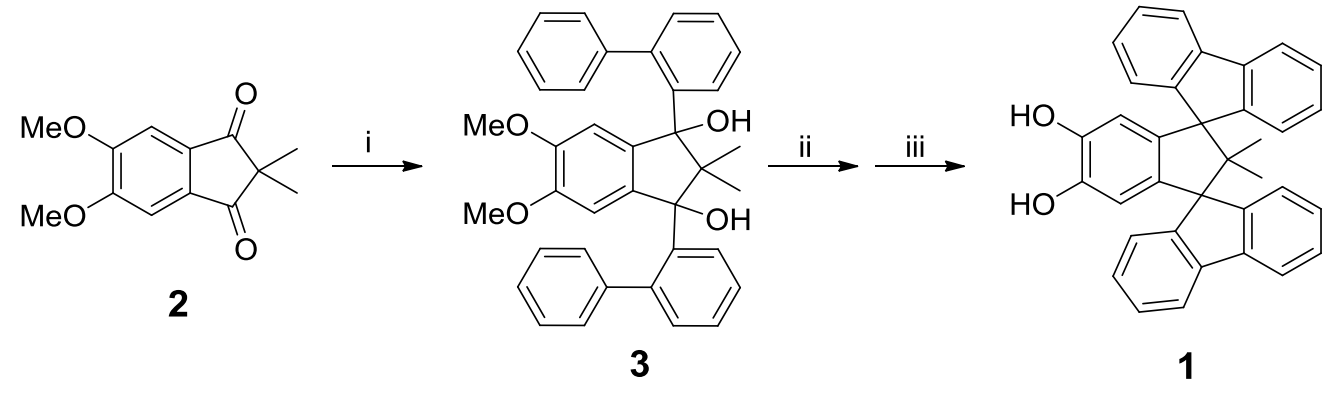

Scheme 2. Proposed route to catechol 1. Reagents. i. Grignard reagent from 2-bromobiphenyl, ii. $\mathrm{H}^{+}$; iii. $\mathrm{BBr}_{3}$. 


\section{Result and Discussion}

The precursor 5,6-dimethoxy-1,3-indandione 2 was readily prepared in moderate yield (42\%) from the reaction between veratrol and 2,2-dimethylmalonic acid in polyphosphoric acid. ${ }^{5}$ Despite reassuring literature precedents for the analogous simple addition of excess phenyl magnesium bromide reagent to 1,3-indandione, ${ }^{6}$ the attempted synthesis of $\mathbf{1}$ did not proceed as expected. The only product (33\% from 2) isolated from the product mixture of the reaction between 2 and the 2-biphenylmagnesium bromide, followed by a work-up in strong acid, gave highly complex ${ }^{1} \mathrm{H}$ and ${ }^{13} \mathrm{C}$ NMR spectra despite providing encouraging IR (no band corresponding to $\mathrm{C}=\mathrm{O}$ stretch) and mass spectra $\left(\left[\mathrm{M}^{+}\right]=254\right.$, which could correspond to loss of $\mathrm{OH}$ from the anticipated product $\mathbf{1})$.

To provide structural elucidation, crystals suitable for analysis by X-ray diffraction (XRD) were obtained by slow diffusion of methanol into a chloroform solution of the product. The single crystal XRD study showed that the product was 1,1-di(biphenyl-2-yl)-5,6-dimethoxy-3(propan-2-ylidene)-1,3-dihydroisobenzofuran 4 (Figure 1). The crystals are monoclinic and belong to the $\mathrm{P} 2{ }_{1} / \mathrm{c}$ space group. The unit cell contains four molecules of $\mathbf{4}$ and four chloroform molecules. Of note within the molecular packing arrangement (Figure 1c) is the directional, $\mathrm{CH}$ $\pi$ interaction between a methoxy group on one molecule and the benzene ring of one of the biphenyl substituents on a neighbouring molecule. Both methoxy groups are also weakly interacting with the included chloroform molecule.

a)

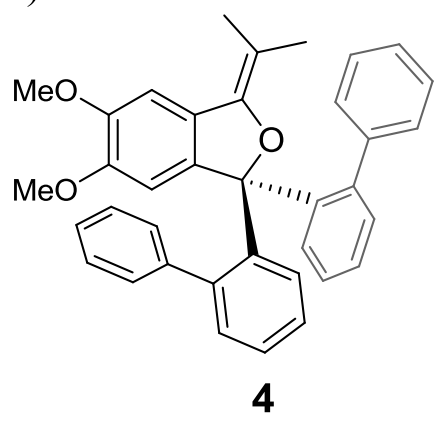

b)

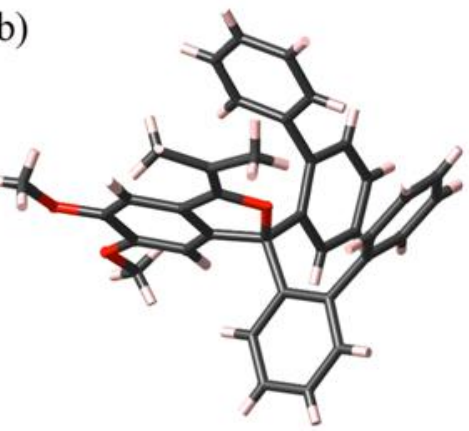

c)

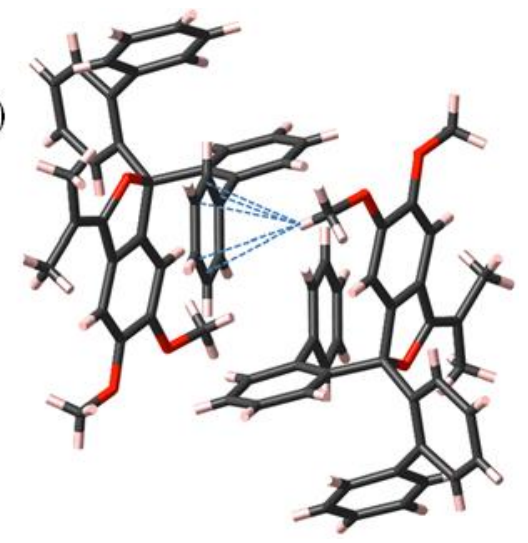

Figure 1. (a) Structure of product 4. (b) Molecular structure of $\mathbf{4}$ as determined by single crystal XRD. (c) Molecular packing showing the main $\mathrm{CH}-\pi$ interaction (included chloroform has been removed for clarity).

Our proposed mechanism to explain the formation of product $\mathbf{4}$ starts with simple Grignard addition to one of the ketone groups of $\mathbf{2}$. This is followed by a retro-aldol reaction that produces a ketone, with consequent ring-opening to form a double bond conjugated to the main aromatic ring. The newly formed ketone then reacts with another molecule of the Grignard reagent. On 
acidification, the easy formation of a triarylmethyl carbocation facilitates the ring closure to give 4. We found no traces of the desired product 3 , probably due to steric congestion prohibiting the addition of the bulky Grignard adducts at the positions adjacent to a quaternary carbon centre. A literature search indicates that a dihydroisobenzofuran product analogous to $\mathbf{4}$ has been previously isolated from the reaction between an excess of phenylmagnesium bromide and 1,3indanedione in addition to the diol resulting from the simple double Grignard reaction, analogous to the originally desired intermediate $3{ }^{7}$ In all other literature examples of this type of reaction only the diol product is reported. ${ }^{6}$

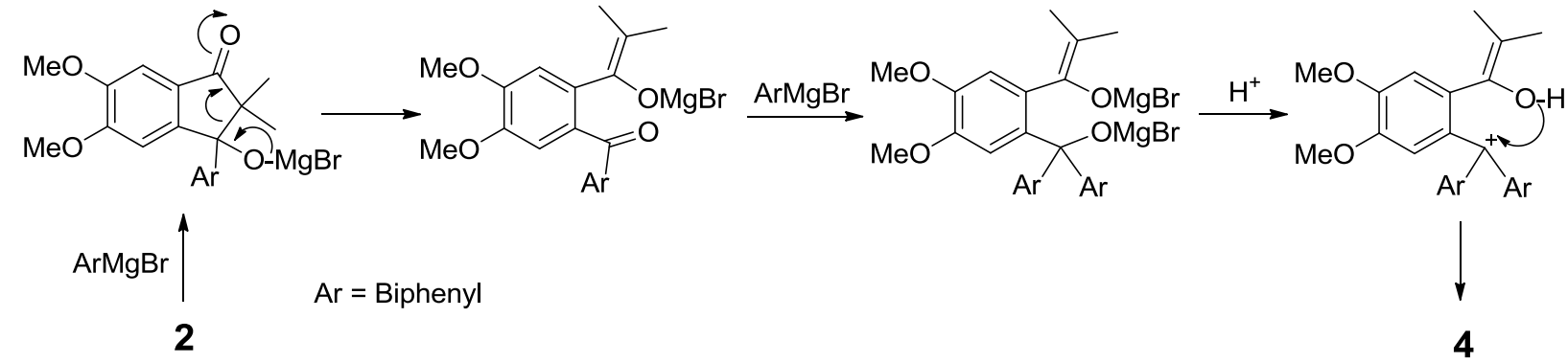

Scheme 3. Proposed mechanism for the formation of 4.

\section{Conclusions}

Unfortunately, the target OMIM precursor 1 could not be prepared by the route shown in Scheme 1 and the unexpected product 4 proved unstable to an attempted demethylation ${ }^{8}$ using $\mathrm{BBr}_{3}$, which led to the formation of a highly coloured reaction mixture and intractable black solids. This prevented its use as a precursor to OMIM formation. However, the observed combination of Grignard addition followed by retro-aldol reaction leading to a highly substituted dihydroisobenzofuran derivative may find other uses for assembling complex molecules.

\section{Experimental Section}

5,6-Dimethoxy-2,2-dimethylindanedione (2). Polyphosphoric acid (100 mL) was heated to 80 ${ }^{\circ} \mathrm{C}$ and 2,2-dimethylmalonic acid $(5.00 \mathrm{~g}, 37.8 \mathrm{mmol})$ and veratrol $(4.18 \mathrm{~g}, 30.3 \mathrm{mmol})$ were added and the mixture was stirred for $3 \mathrm{~h}$. The reaction mixture was poured into ice water (200 $\mathrm{mL})$. The precipitate was filtered under suction and recrystallized from methanol to give the desired product $(2.97 \mathrm{~g}, 42 \%)$ as a white solid, mp $217-219{ }^{\circ} \mathrm{C}\left(224-226{ }^{\circ} \mathrm{C}\right)^{5} \cdot{ }^{1} \mathrm{H}$ NMR $(500$ $\left.\mathrm{MHz}_{\mathrm{CDCl}}\right): \delta=7.32(\mathrm{~s}, 2 \mathrm{H}), 4.02(\mathrm{~s}, 6 \mathrm{H}), 1.27(\mathrm{~s}, 6 \mathrm{H}) \mathrm{ppm} .{ }^{13} \mathrm{C} \mathrm{NMR}\left(125 \mathrm{MHz} ; \mathrm{CDCl}_{3}\right): \delta$ $=203.4$, 156.1, 135.1, 103.5, 56.6, 49.4, 20.3 ppm. IR (DCM, Film): 2974.6, 2938.0, 2359.5, 
$2342.6,1732.7,1695.6,1652.7,1580.8,1558.7,1502.8,1475.3,1451.6,1379.3,1315.7$, $1238.56,1224.6,1166.7,1106.9,1044.7,1004.7$. EI-MS $(\mathrm{m} / \mathrm{z}): 235[\mathrm{M}+\mathrm{H}]^{+}$.

5,6-Dimethoxy-1,1-bis(2-phenylphenyl)-3-(propan-2-ylidene)-1,3-dihydro-2-benzofuran (4). To a two-necked round bottom flask was added 2 (1.26 g, $5.4 \mathrm{mmol})$ and dry THF (60 mL). 2Biphenylmagnesium bromide $(5.52 \mathrm{~g}, 21.6 \mathrm{mmol})$ in dry THF $(60 \mathrm{~mL})$ was added slowly at $0{ }^{\circ} \mathrm{C}$ under vigorous stirring and the mixture was stirred at room temperature for $16 \mathrm{~h}$. The reaction was quenched with water $(150 \mathrm{~mL})$ and the THF was evaporated under reduced pressure. The precipitate was filtered under suction and dried. The crude product was stirred in Eaton's reagent (7.7 wt \% phosphorus pentoxide solution in methanesulfonic acid, $50 \mathrm{~mL}$ ) for $16 \mathrm{~h}$, quenched carefully with water $(150 \mathrm{~mL})$ and extracted with DCM $(2 \times 150 \mathrm{~mL})$. The organic layers were evaporated under reduced pressure to give the crude product which was purified by column chromatography (hexane/EtOAc, 9:1) to give the title compound $(0.84 \mathrm{~g}, 30 \%)$ as a white solid, mp $193-195{ }^{\circ} \mathrm{C} .{ }^{1} \mathrm{H}$ NMR $\left(500 \mathrm{MHz}, \mathrm{CDCl}_{3}\right): \delta=7.14(\mathrm{~m}, 18 \mathrm{H}), 6.94(\mathrm{~s}, 1 \mathrm{H}), 6.68(\mathrm{~s}, 1 \mathrm{H})$, $3.94(\mathrm{~s}, 3 \mathrm{H}), 3.85(\mathrm{~s}, 3 \mathrm{H}), 1.65(\mathrm{~s}, 3 \mathrm{H}), 1.17(\mathrm{~s}, 3 \mathrm{H}) \mathrm{ppm} .{ }^{13} \mathrm{C} \mathrm{NMR}\left(125 \mathrm{MHz} ; \mathrm{CDCl}_{3}\right): \delta=$ 149.5, 148.7, 147.7, 143.6, 138.84, 133.1, 131.4, 128.1, 127.9, 126.7, 125.7, 108.14, 105.5, 102.51, 93.7, 56.6, 20.2, 18.4 ppm. IR (DCM Film): 3055.2, 2917.1, 2848.0, 2357.8, 1592.0, 1498.7, 1460.8, 1308.9, 1264.0, 1212.2, 1170.7, 1132.8, $1101.9 \mathrm{~cm}^{-1}$. LRMS (EI), m/z: 525 $[\mathrm{M}+\mathrm{H}]^{+}$. HRMS Calc. for $\mathrm{C}_{37} \mathrm{H}_{32} \mathrm{O}_{3}$ 524.2351, found 524.2341 (the accurate mass value differs slightly from the permitted $5 \mathrm{ppm}$ window, probably, due to the inherent $\mathrm{CHCl}_{3}$ ).

Crystals of 4 were prepared by the slow diffusion of $\mathrm{MeOH}$ into a $\mathrm{CHCl}_{3}$ solution of the complex. Single-crystal XRD data were collected at $150 \mathrm{~K}$ using graphite monochromated MoK $\alpha$ radiation on a Bruker-Nonius Kappa CCD diffractometer with an Oxford Cryosystems cooling apparatus. The structure was solved from these data by direct methods and refined using SHELX-97. ${ }^{9}$ Crystal size $0.65 \times 0.06 \times 0.06 \mathrm{~mm}$, monoclinic, space group $P 2 / / c, a=12.4685(5)$, $\mathrm{b}=18.3564(10), \mathrm{c}=14.3155(8) \AA, \beta=96.004(3), V=3258.51 \AA^{3}, \mathrm{Z}=4, \mu=0.318 \mu \mathrm{m}^{-1}, 6377$ reflections measured, 2707 unique reflections $\left(R_{\text {int }}=0.0570\right)$, 9528 reflections with $I>2 \sigma(I), R=$ 0.0775 and $\omega R 2=0.1497$ (observed data), $R=0.1036$ and $\omega R 2=0.1592$ (all data). The asymmetric unit contains one molecule of 4 and a $\mathrm{CHCl}_{3}$ molecule. The unit cell contains 4 molecules of $\mathbf{4}$ and 4 of $\mathrm{CHCl}_{3}$. The crystal structure of $\mathbf{4}$ has been submitted to the Cambridge Crystallographic Data Centre (Deposition number CCDC 883926).

\section{Acknowledgements}

CGB and MC thank the EPSRC for funding (Grants EP/G01244X and EP/H024034/1). 


\section{References}

1. McKeown, N. B. J. Mater. Chem. 2010, 20, 10588.

2. Budd, P. M.; Ghanem, B. S.; Makhseed, S.; McKeown, N. B.; Msayib, K. J.; Tattershall, C. E. Chem. Commun. 2004, 230.

3. McKeown, N. B.; Budd, P. M. Macromolecules 2010, 43, 5163.

4. (a) Carta, M.; Msayib, K. J.; Budd, P. M.; McKeown, N. B. Org. Lett. 2008, 10, 2641. (b) Carta, M.; Msayib, K. J.; McKeown, N. B. Tetrahedron Lett.2009, 50, 5954. (c) Carta, M.; Raftery, J.; McKeown, N. B. J. Chem. Crystal. 2011, 41, 98.

5. Maslak, P.; Varadarajan, S.; Burkey, J. D. J. Org. Chem. 1999, 64, 8201.

6. (a) Brutcher, F. V.; Cenci, H. J. J. Org. Chem. 1956, 21, 1543. (b) Geissman, T. A.; Tulagin, V. J. Am. Chem. Soc. 1941, 63, 3352. (c) Huffman, K. R.; Ullman, E. F. J. Am. Chem. Soc. 1967, 89, 5629.

7. Schonber. A; Mamluk, M. Chem. Ber. Rec. 1973, 3, 106, 849.

8. McOmie, J. F. W.; Watts, M. L.; West, D. E. Tetrahedron 1968, 24, 2289.

9. Sheldrick, G. M. Acta Crystallogr. Sect. A 2008, 64, 112. 